Citation: A. Mulero-Aparicio, A. Trapero, F.J. López-Escudero (2020) A nonpathogenic strain of Fusarium oxysporum and grape marc compost control Verticillium wilt of olive. Phytopathologia Mediterranea 59(1): 159-167. doi: 10.14601/Phyto-11106

Accepted: February 19,2020

Published: April 30, 2020

Copyright: (C) 2020 A. Mulero-Aparicio, A. Trapero, F.J. López-Escudero. This is an open access, peer-reviewed article published by Firenze University Press (http://www.fupress.com/pm) and distributed under the terms of the Creative Commons Attribution License, which permits unrestricted use, distribution, and reproduction in any medium, provided the original author and source are credited.

Data Availability Statement: All relevant data are within the paper and its Supporting Information files.

Competing Interests: The Author(s) declare(s) no conflict of interest.

Editor: Epaminondas Paplomatas, Agricultural University of Athens, Greece.
Research Paper

\section{A non-pathogenic strain of Fusarium oxysporum and grape marc compost control Verticillium wilt of olive}

\author{
Antonio MUlero-APARICIO*, Antonio TRAPERO, Francisco Javier \\ LÓPEZ-ESCUDERO \\ Departamento de Agronomía, ETSIAM, Universidad de Córdoba, Campus de Rabanales, \\ Edif. C4, 14071 Córdoba, Spain \\ *Corresponding author: z32muapa@uco.es
}

Summary. Verticillium wilt of olive (VWO), caused by the widespread soil-borne fungus Verticillium dahliae Kleb., is currently the most serious disease affecting olive trees (Olea europaea L.) in all production areas. An integrated management strategy using eco-friendly approaches such as genetic resistance and biological control is considered the most advisable approach for controlling the disease in commercial olive orchards. This study evaluated a non-pathogenic strain of F. oxysporum (FO12) and the grape marc compost CGR03 for reducing inoculum density of $V$. dahliae and the disease progress in two olive cultivars with different VWO resistance levels. The experiment was conducted under semi-controlled conditions, using a naturally infested soil with two inoculum densities of $V$. dahliae. The biocontrol treatments (FO12 and CGR03) were previously selected out of 220 natural products as two of the most effective treatments against the pathogen. FO12 and CGR03 treatments significantly reduced pathogen inoculum density in comparison with that of the control $(P=0.05)$, with minimum microsclerotium amounts of $0.13 \mathrm{~g}^{-1}$ for FO12 and $0.53 \mathrm{~g}^{-1}$ for CGR03, during the experimental period. CGR03 reduced the progression of the disease compared with that in the control $(P=0.05)$, and FO12 achieved complete control of $\mathrm{VWO}$, since no plants treated with this biological control strain developed VWO symptoms. This study highlights the effectiveness of these biocontrol treatments, and the potential use of ecofriendly approaches for control of VWO.

Keywords. Biocontrol agents, Olea europaea, organic amendment, microsclerotia, Verticillium dahliae.

\title{
ABBREVIATIONS:
}

ANOVA: Analysis of variance; BCAs: Biological control agents; DAP: Days after planting; HID: High inoculum density; ID: Inoculum density; LID: Low inoculum density; LSD: Least significant difference; MS: Microsclerotia; MSPA: Modified sodium polypectate agar medium; PDA: Potato dextrose agar; RAUDPC: Relative area under the disease progress curve; RAUIPC: Relative area under the inoculum progress curve; VWO: Verticillium wilt of olive. 


\section{INTRODUCTION}

The widespread soil-borne fungus Verticillium dahliae Kleb. is known to cause vascular diseases in several crops with agronomic value (Pegg and Brady, 2002). Verticillium wilt of olive (VWO) is the most serious disease caused by this pathogen affecting olive trees (Olea europaea L.) in all olive-producing areas, causing significant economic losses and plant death (López-Escudero and Mercado Blanco, 2011). In the infested olive groves of the Guadalquivir valley (Andalusia, Spain), this disease has reached an average incidence of $20 \%$ (López-Escudero et al., 2010).

Since there is no efficient control of VWO when control measures are individually applied, an integrated management strategy is the most advisable approach to reducing the disease in commercial olive crops (LópezEscudero and Mercado Blanco, 2011). Within this strategy, and due to current environmental concerns, ecofriendly approaches such as cultural practices, genetic resistance and biological control have acquired increased relevance. The genetic resistance levels of olive cultivars against VWO have been assessed in previous studies. López-Escudero et al. (2004) reported that cv. 'Picual' and 'Arbequina' are highly susceptible to the defoliating pathotype of $V$. dahliae when they are artificially inoculated by root dipping. Additionally, the relationship between inoculum density (ID) of $V$. dahliae in infested soils and the resistance among olive cultivars was confirmed in several studies. López-Escudero and BlancoLópez (2007) reported that 'Picual' was extremely susceptible to $V$. dahliae when planted in soils with low ID, while 'Arbequina' was moderately resistant under the same conditions (Trapero et al., 2013b). This relationship was confirmed in a study carried out in commercial olive orchards (Roca et al., 2015).

Although there are numerous studies related to the biological control of $V$. dahliae, few have addressed the use of biocontrol treatments against VWO. The use of Pseudomonas spp. (Mercado-Blanco et al., 2004; Triki et al., 2012; Gómez-Lama et al., 2017) and Trichoderma spp. (Lima et al., 2007; Jiménez-Díaz et al., 2009) have been reported as promising biological control agents (BCAs) against VWO. Preliminary studies on the use of organic amendments against VWO have been conducted (Vitullo et al., 2013). An extensive screening was conducted to evaluate the effectiveness of 220 natural compounds, including microorganisms (Lozano-Tovar et al., 2013; Varo et al., 2016), organic amendments (Varo-Suárez et al., 2018) and plant extracts (Varo et al., 2017), against $V$. dahliae, in in vitro and in planta experiments under controlled conditions. The most effective treatments were evaluated under field conditions (Mulero-Aparicio et al., 2020), as the only study that has evaluated biological control treatments against VWO in natural conditions. From these two studies, a non-pathogenic strain of Fusarium oxysporum, designated FO12, and a grape marc compost, labelled CGR03, were selected as two of the most effective treatments against the pathogen. However, further studies evaluating these products under semi-controlled and different field conditions are essential for demonstrating their effectiveness against VWO.

Knowledge of the interactions between different disease management strategies, such as genetic resistance or biological control, used for integrated control of VWO is important for achieving efficient control of the disease. However, the combined effects of these two strategies remains unknown. The main objective of the present study was to evaluate the effect of two biological treatments, the non-pathogenic strain of F. oxysporum FO12 and the grape marc compost CGR03, on the progression of ID of $V$. dahliae, and on the development of VWO, using two olive cultivars with different levels of genetic resistance to the disease.

\section{MATERIALS AND METHODS}

\section{Plant material}

One-year-old rooted olive plants of cv. 'Picual' and 'Arbequina' (respectively susceptible and moderately susceptible to VWO) (Trapero et al., 2013a) were used for the experiment. These plants were obtained from a commercial nursery producing plants that were certified free of $V$. dahliae and other olive pathogens. At planting time, the plants were $1 \mathrm{y}$ old and 1.0 to $1.1 \mathrm{~m}$ high, each with a single trunk and three or four secondary branches.

\section{Naturally infested soil and inoculum density estimation}

The soil used in this study was collected from a commercial field previously cultivated with cotton over the last 50 years, located in Villanueva de la Reina (UTM coordinates X: 38.012845; Y: 3.909219) in Jaen Province (Andalusia, southern Spain).

To estimate the ID of $V$. dahliae in this soil, five soil sub-samples of $\approx 500 \mathrm{~g}$ were collected from the upper 30 $\mathrm{cm}$ of soil, using a cylindrical soil auger. Sub-samples were mixed, air-dried at room temperature, and sieved $(0.8 \mathrm{~mm}$ mesh) to remove large particles. Inoculum density of $V$. dahliae in the soil was estimated by wet sieving (Huisman and Ashworth, 1974) onto modified sodium polypectate agar medium (MSPA) (Butterfield and DeVay, 
1977). Three samples ( $25 \mathrm{~g}$ each) of the naturally infested soil were suspended in $100 \mathrm{ml}$ of distilled water, shaken at $270 \mathrm{rpm}$ for $30 \mathrm{~min}$ at room temperature and filtered through 150 and $35 \mu \mathrm{m}$ sieves. The residue retained on the $35 \mu \mathrm{m}$ sieve was recovered in $100 \mathrm{ml}$ of distilled water. Part of this suspension was then plated across ten plates of MSPA ( $1 \mathrm{ml} / \mathrm{plate})$, and the plates were incubated for $14 \mathrm{~d}$ at $24 \pm 2^{\circ} \mathrm{C}$ in the dark. Soil residues were removed from the agar surfaces under running tap water, and colonies of $V$. dahliae were counted using a stereomicroscope (Nikon SMZ-2T). The ID in soil was estimated from the number of $V$. dahliae colonies counted per sample and was expressed as microsclerotia (MS) per gram of soil $\left(\mathrm{MS} \mathrm{g}^{-1}\right)$ (López-Escudero and Blanco-López, 2005).

\section{Biocontrol treatments}

Two biocontrol treatments were evaluated in this study. The grape marc compost CGR03 and the nonpathogenic strain of Fusarium oxysporum FO12 were selected due to their suppressive effects on VWO demonstrated in previous in vitro and in vivo experiments (Varo et al., 2016; Varo-Suárez et al., 2018; Mulero-Aparicio et al., 2019a).

\section{Grape marc compost CGR03}

The organic amendment CGR03 was provided by the agri-food cooperative "Cooperativa San Acacio", Montemayor, Córdoba (southern Spain). To produce the compost, grape marc wastes consisting of grape skins, seeds and stems of the grapevine cv. 'Pedro Ximénez' from the wine industry were used as feedstock. Grape marc is collected annually from August to September and composted in insulated bins each of $15 \mathrm{~m}^{3}$ for 8 months. When the compost temperature fell below $60^{\circ} \mathrm{C}$ at a depth of $50 \mathrm{~cm}$, the compost was turned to promote aeration and homogeneity and to renew the composting process. Compost was collected for use when the temperature permanently fell below $40^{\circ} \mathrm{C}$ (maturation/recolonization phase). The $\mathrm{pH}$ of the compost was 6.9 , determined in 1:5 (v:v) compost/water extract. Before use, the compost was proven to be mature and stable by measuring its temperature $\left(30-35^{\circ} \mathrm{C}\right.$ for mature compost) to avoid phytotoxicity (Mehta et al., 2014; Varo-Suárez et al., 2018).

Non-pathogenic strain of Fusarium oxysporum

The non-pathogenic F. oxysporum strain FO12, from to the fungal collection of the Department of Agronomy,
University of Córdoba (Spain), was used as a BCA. The isolate was prepared from a single-spore stock culture maintained on potato dextrose agar (PDA; Difco Laboratories) slants at $4^{\circ} \mathrm{C}$. Seven-d-old cultures of F. oxysporum incubated on PDA at $25^{\circ} \mathrm{C}$ under a 12 -h photoperiod of fluorescent light were used as the inoculum source. To prepare the inoculum suspension of FO12 needed for the treatment, a $2 \mathrm{~L}$ Erlenmeyer flask containing $1 \mathrm{~L}$ of potato dextrose broth (PDB; Difco Laboratories) was inoculated with a conidium suspension from a $7 \mathrm{~d}$ PDAmycelium culture of the BCA. The conidium concentration of the inoculated PDB flask was adjusted to $2 \times 10^{5}$ conidia $\mathrm{mL}^{-1}$ (assessed by haemocytometer) and incubated at $25^{\circ} \mathrm{C}$ on an orbital shaker (Grant bio PSU-20i, Grant Instruments) at $90 \mathrm{rpm}$ for $7 \mathrm{~d}$. After incubation, the FO12 inoculum was adjusted to $10^{6}$ conidia $\mathrm{mL}^{-1}$ prior to application.

\section{Semi-controlled conditions and experimental design}

The experiment was conducted under semi-controlled conditions in a set of microplots located at the 'Campus de Rabanales' at the University of Córdoba (UCO, Córdoba Province, Andalusia region, southern Spain. UTM coordinates X: 37.919056; Y: -4.724306) from March 2015 to January 2017. The setup consisted of a line of 18 cement and brick containers (microplots) built on the ground. Each container was of $1 \mathrm{~m}^{3}$ capacity and was open at the bottom, and the line of containers was oriented north to south and protected from rain and excessive sun by a metal rooftop structure. This microplot system has been used previously in epidemiological studies of VWO (López-Escudero and Blanco-López, 2007; Pérez-Rodriguez et al., 2015).

The ID of $V$. dahliae in the original naturally infested soil (above) and used in this experiment was estimated at $168 \mathrm{MS} \mathrm{g}^{-1}$. To study the influence of the initial ID of $V$. dahliae on the effectiveness of the two biocontrol treatments, the soil was diluted to obtain two different IDs. The original naturally infested soil was mixed with V. dahliae-free sand at two rates: 1:2 and 1:10 (v:v; infested soil:sand). Both mixtures were separately homogenized by mixing using a motor hoe (Zeppelin ${ }^{\circledR} 1117 \mathrm{HP}$ ) at the experimental site. The initial ID of the two mixtures was determined (as above) to be $83.6 \mathrm{MS} \mathrm{g}^{-1}$ for the high inoculum density (HID) mixture and 23.6 $\mathrm{MS} \mathrm{g}^{-1}$ for low inoculum density (LID) mixture.

Each microplot was filled with $800 \mathrm{~kg}$ of the required soil mixture (bulk density $=1,300 \mathrm{~kg} \mathrm{~m}^{3}$ ), and eight olive plants were planted in each microplot, four of each of the two cultivars. A total of 18 microplots were used in this experiment, which was carried out in a split-split- 
plot design with three blocks, each block composed of six microplots, two levels of ID (HID and LID) as the main plot, three treatments (FO12, CGR03 or water treated control) as the subplot and two olive cvs. ('Arbequina' or 'Picual') as the sub-subplot, with a total of 144 olive plants (72 of each cultivar).

\section{Plant establishment and treatment application}

Olive plants were transplanted in March 2015, and microplots were treated with the grape marc compost (CGR03) or with the non-pathogenic strain of F. oxysporum (FO12). To prevent damage to the roots of the olive plants, CGR03 was incorporated into the soil just before planting as an organic amendment, by tillage (to $30 \mathrm{~cm}$ depth) with a manual hoe at a rate of $20 \%$ (v:v) (i.e., $60 \mathrm{~L} /$ microplot). Subsequently, microplots treated with CGR03 were planted and watered with $30 \mathrm{~L}$ of tap water. The treatment with FO12 was applied just after planting by watering each microplot with $30 \mathrm{~L}$ of the inoculum suspension $\left(10^{6}\right.$ conidia $\left.\mathrm{mL}^{-1}\right)$. Microplots treated with $30 \mathrm{~L}$ of tap water were used as the experimental controls. Treatments were applied twice a year at the beginning of each spring and autumn season, until the end of the experiment in January 2017. The subsequent treatments with CGR03 were applied at less than the initial dose (i.e., $30 \mathrm{~L} /$ microplot) by superficial tillage to prevent damage to the plants. The microplots were irrigated each week during spring, summer and autumn and biweekly during the winter season, according to Pérez-Rodríguez et al. (2015).

\section{Assessment of inoculum density progress}

The ID of $V$. dahliae in the soil of each microplot was periodically quantified to evaluate the ID progression over time in each treatment. A total of nine soil samples were collected during the experiment. Initially, soil samples were collected at 15,30 and $60 \mathrm{~d}$ after planting (DAP). From $60 \mathrm{~d}$ until the end of the experiment, samples were collected at the beginning of each season, which corresponded to $100,180,250,390,470$ or 570 DAP. At each sampling time, four soil sub-samples (100 g) per microplot were collected, using a cylindrical (3.5 $\mathrm{cm} \times 22 \mathrm{~cm}$ ) auger at a soil depth of 20 to $30 \mathrm{~cm}$. The sub-samples from each microplot were mixed to obtain a homogenous sample, which was then processed to estimate the ID using the wet sieving method described above. The randomized area under the inoculum progress curve (RAUIPC) for each treatment was calculated by the trapezoidal integration method (Campbell and
Madden, 1990) from all ID values obtained from the nine soil sampling times.

\section{Disease assessments}

The first symptoms of VWO were observed 4 months after planting, in July 2015. The plants in the experiment were surveyed each week for wilt symptoms, from disease onset until the end of the experiment in January 2017. Disease severity was estimated using a 0 to 16 rating scale, according to the proportions of plant tissue affected by chlorosis, necrosis or defoliation. The scale estimated the percentage of affected tissue using four main categories $(\leq 25,26-50,51-75$, or $76-100 \%)$, with four ratings per category. Each scale value represented the number of sixteenths of affected plant area. The scale values (X) were linearly related to the percentage of affected tissue (Y) using the equation $\mathrm{Y}=6.25 \mathrm{X}-3.125$ (Varo-Suárez et al., 2018). At the end of the disease assessments, the relative area under the disease progress curves (RAUDPC) were calculated from the disease severity values, using the trapezoidal integration method (Campbell and Madden, 1990). In addition, plant infection by $V$. dahliae was confirmed by isolating the fungus from the affected shoots of diseased plants, as described by Varo-Suárez et al. (2018).

\section{Data analyses}

Analyses of variance (ANOVA) were carried out for the disease parameters (final disease severity and RAUDPC) and of the inoculum progress data (final ID and RAUIPC). Values of these parameters met the assumptions of normality and homogeneity of variances for these analyses. Final disease severity and RAUDPC data were analysed according to a split-split-plot experimental design, with the initial IDs as the main plots, treatments as the subplots and the cultivars as the subsubplot factors. The data of final ID and RAUIPC were arranged in a split-plot design with the initial ID levels as the main plots and treatments as the subplots. When the ANOVA showed statistically significant differences among treatments, values were compared using Fisher's protected least significant difference (LSD) at $P=0.05$. All statistical analyses were carried out using Statistix 10 (Analytical Software, 2013).

\section{RESULTS}

The ID progress of $V$. dahliae in naturally infested soils after the application of CGR03 and FO12 is repre- 
sented in Figure 1. The effectiveness of CGR03 in reducing the ID of $V$. dahliae was observed at the first sampling time (15 DAP) for both initial inoculum densities (HID and LID). At this time, in the case of a high initial pathogen ID (HID), CGR03 reduced $(P=0.0006)$ the ID in comparison with that in the control and from the FO12 treatment, with an ID of $2.3 \mathrm{MS} \mathrm{g}^{-1}$. A more pronounced effect from CGR03 compared with that from FO12 was observed at the first stages of the experiment (Figure 1a). On the other hand, FO12 gave a significant reduction in ID at 100 DAP $(P=0.0059)$ compared with the control, with a concentration of $23.9 \mathrm{MS} \mathrm{g}^{-1}$ (Figure 1a). Fluctuations in the ID of $V$. dahliae during the sampling period were observed for all treatments tested, reaching minimum values of 39.2 for the control (15 DAP), 0.8 from CGR03 (470 DAP), and $0.53 \mathrm{MS} \mathrm{g}^{-1}$ (470 DAP) from FO12. At the last sampling (570 DAP), differences $(P<0.0001)$ were found among treatments, with CGR03 resulting in the greatest reduction in ID, with a final ID of $1.9 \mathrm{MS} \mathrm{g}^{-1}$.

When the initial ID was low (LID), both biocontrol treatments reduced $(P=0.0005)$ the ID of $V$. dahliae in

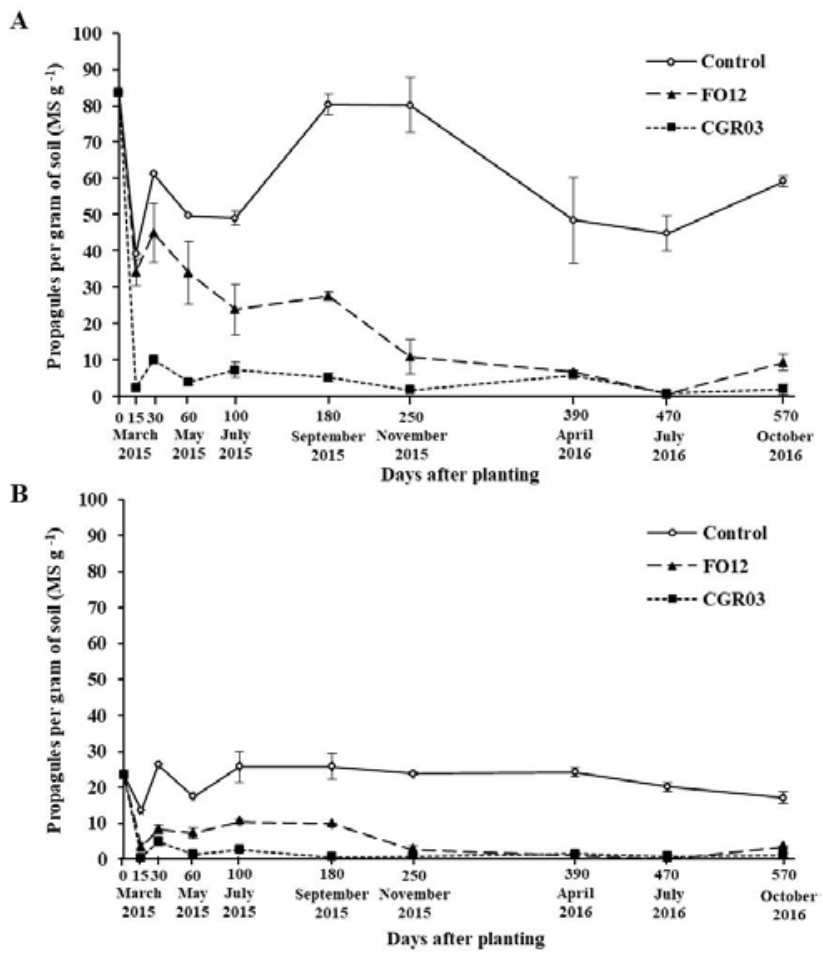

Figure 1. Progress of inoculum density (ID) of Verticillium dahliae at nine sampling times (from 15 to 570 days after planting), in naturally infested soils with a) high inoculum density (HID) or b) low inoculum density (LID), after treatment with FO12 or CGR03. For each sampling time, the means of three soil samples per treatment are shown, and the bars are standard errors of the means. comparison with that in the control at $15 \mathrm{DAP}$, with IDs of 13.6 MS g-1 for the control, 3.4 $\mathrm{MS} \mathrm{g}^{-1}$ from the FO12 treatment, and $0.5 \mathrm{MS} \mathrm{g}^{-1}$ from CGR03 (Figure 1b). The ID of $V$. dahliae in soil treated with each of the biocontrol products remained less $(P=0.0003)$ than that in the control until the end of the experiment, reaching final IDs of 17.2 MS g${ }^{-1}$ for the control, 3.6 $\mathrm{MS} \mathrm{g}^{-1}$ from FO12, and $1.2 \mathrm{MS} \mathrm{g}^{-1}$ from CGR03. The CGR03 treatment also gave a greater reduction in the viable inocula of $V$. dahliae in this case (Figure 1b). In LID soil, fluctuations in ID during the experiment occurred from all the treatments, with minimum ID values of $13.6 \mathrm{MS} \mathrm{g}^{-1}$ for the control (15 DAP), $0.53 \mathrm{MS} \mathrm{g}^{-1}$ from CGR03 (15 DAP) and $0.13 \mathrm{MS} \mathrm{g}^{-1}$ from FO12 (470 DAP) (Figure 1b).

The initial ID had no effect on RAUIPC ( $P=$ $0.9224)$, but statistically significant differences were found between treatments (HID, $P=0.0004$ and LID, $P<0.0001$ ). In both cases (HID and LID), CGR03 was the most effective treatment for reducing the ID, giving significantly lower values of RAUIPC than those from FO12 and the control (respectively, 7.6 and 7.4\% for HID and LID; Figure 2a and $b$ ).

VWO symptoms were first observed in control plants 17 weeks after planting (Figure 3a). A delay of symptom onset was observed in plants treated with CGR03. For microplots containing LID of $V$. dahliae, VWO were first observed in the control and CGR03-treated plants 7 months after planting (Figure 3b). Reisolations from shoots of diseased plants confirmed their infection by $V$. dahliae. There were no significant differences between the two initial pathogen ID levels and final disease severity $(P=0.4557)$ or RAUDPC $(P=0.1993)$. Similarly, no significant differences in final disease severity were

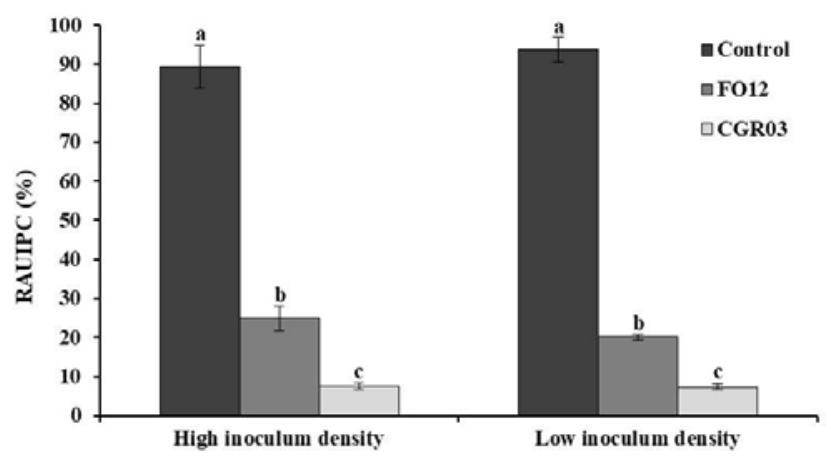

Figure 2. Mean relative area under inoculum progress curves (RAUIPC, \%) in naturally infested soils with high Verticillium dahliae inoculum density (HID) or inoculum density (LID) for each treatment at $570 \mathrm{~d}$ after planting. For each treatment, the histogram is the mean of three replications. Different letters indicate statistically significant differences $(P=0.050$, according to Fisher's protected LSD test, and the bars are the standard errors of the means. 

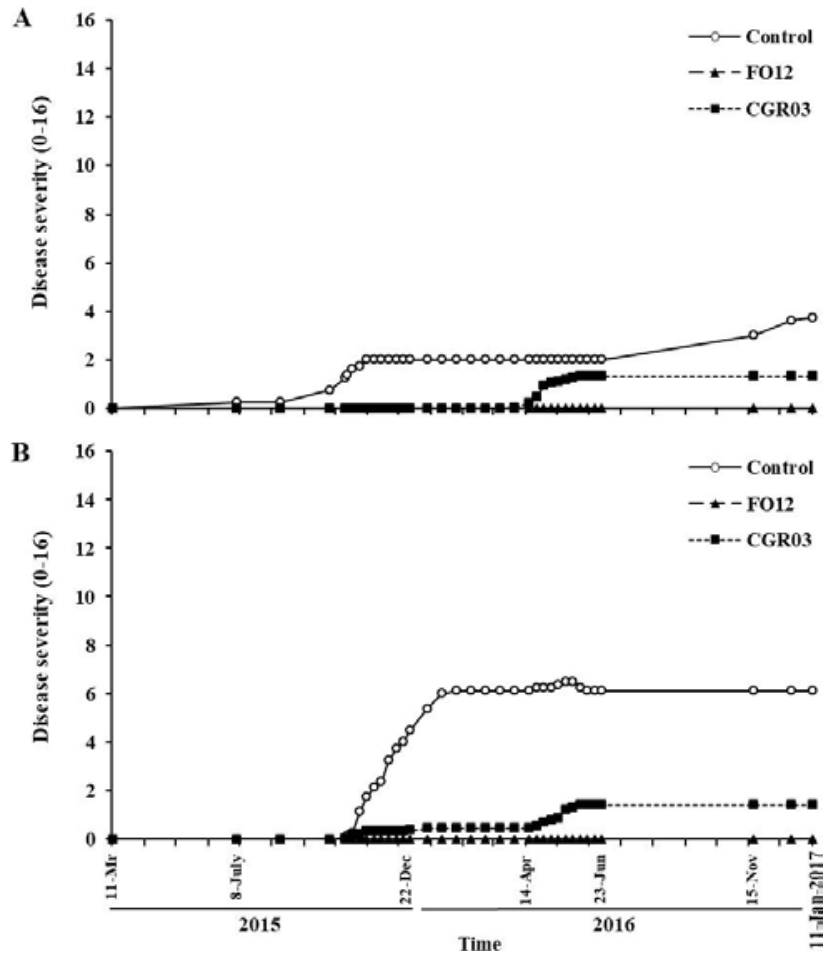

Figure 3. Progress of Verticillium wilt severity of in olive plants grown in naturally infested soils with a) high inoculum density (HID) and b) low inoculum density (LID) of Verticillium dahliae during 2 years under semi-controlled conditions, after treatment with the non-pathogenic Fusarium oxysporum strain FO12 and the grape marc compost CGR03. Disease severity was estimated based on a $0-16$ scale $(0=$ no lesions, $16=94-100 \%$ of canopy with symptoms). Each datum is the mean of 24 plants.

found between cv. 'Picual' and 'Arbequina' $(P=0.2632)$, or RAUDPC $(P=0.5483)$. Data for each disease parameter (severity and RAUDPC) for both cultivars were grouped for statistical analyses (Table 1) and significant differences between treatments were observed. The plants grown in the microplots treated with CGR03 or FO12 showed had reduced disease severity $(P=0.0190)$ and RAUDPC $(P=0.0054)$ compared with those of the control (Table 1). The treatment with FO12 achieved complete control of the disease, as no plants treated with this BCA showed VWO symptoms (Table 1).

\section{DISCUSSION}

Verticillium wilt of olive is the most important disease affecting olive groves in Mediterranean countries. To date, there is no effective control measure for this disease when the control is individually applied. In this study, the non-pathogenic F. oxysporum strain FO12 and
Table 1. Disease-related parameters for olive plants grown in naturally infested soil by Verticillium dahliae during along 2 years under semi-controlled conditions, after treatments with the non-pathogenic strain of Fusarium oxysporum FO12 and the grape marc compost CGR03.

\begin{tabular}{lccc}
\hline Initial ID & Treatment & $\begin{array}{c}\text { Disease } \\
\text { severity }(\%)^{\mathrm{b}}\end{array}$ & $\begin{array}{c}\text { RAUDPC } \\
(\%)^{\mathrm{c}}\end{array}$ \\
\hline $\begin{array}{l}\text { High inoculum density } \\
\left(\mathrm{HID}, 83.6 \mathrm{MS} \mathrm{g}^{-1}\right)\end{array}$ & Control & $23.0 \pm 15.2 \mathrm{a} 16.1 \pm 11.8 \mathrm{a}$ \\
& CGR03 & $8.1 \pm 5.2 \mathrm{~b}$ & $5.0 \pm 3.2 \mathrm{~b}$ \\
& FO12 & $0.0 \pm 0.0 \mathrm{c}$ & $0.0 \pm 0.0 \mathrm{c}$ \\
\hline $\begin{array}{l}\text { Low inoculum density (LID, } \\
\text { 23.6 MS g }\end{array}$ & Control & $37.1 \pm 15.1 \mathrm{a} 36.2 \pm 14.5 \mathrm{a}$ \\
& CGR03 & $8.6 \pm 5.2 \mathrm{~b}$ & $6.2 \pm 3.9 \mathrm{~b}$ \\
& FO12 & $0.0 \pm 0.0 \mathrm{c}$ & $0.0 \pm 0.0 \mathrm{c}$ \\
\hline
\end{tabular}

${ }^{\text {a }}$ Initial inoculum density (ID) of V. dahliae in the two soil mixtures used in the experiment.

b Final disease severity (\%) \pm standard error 22 months after planting based on a $0-16$ rating scale $(0=$ no lesions, $16=94-100 \%$ of canopy with symptoms).

${ }^{c}$ Relative area under the disease progression curve (RAUDPC, \%) \pm standard error developed over the assessment period (22 months).

${ }^{b, c}$ In each column, data represent the mean of 24 replicated plants per treatment. Mean values followed by the same letter do not differ significantly according to Fisher's protected LSD test at $P=0.05$.

the suppressive grape marc compost CGR03 have been evaluated for effectiveness in controlling this major disease, under semi-controlled conditions. These biocontrol products were selected from previous studies since they were the most effective at suppressing $V$. dahliae growth in vitro and in planta (Varo et al., 2016; Varo-Suárez et al., 2018; Mulero-Aparicio et al., 2019a), and under field conditions (Mulero-Aparicio et al., 2020). This study is a final step indicating the potential of these treatments before their evaluation under different scenarios of natural infections or field conditions, where olive producers urgently require feasible control strategies.

Results obtained in this study agree with those reported by Varo-Suárez et al. (2018) and Mulero-Aparicio et al. (2019a), where CGR03 and FO12 were two of the most effective products for reducing the ID of $V$. dahliae in two different soils in an in vitro experiment. Similarly, these results agree with those of Mulero-Aparicio et al. (2020), where these treatments reduced ID of the pathogen in natural conditions. Results from the present study also indicate that the CGR03 treatment, compared with FO12, achieved a greater reduction in ID during the first stages of the experiment when the initial ID was greatest (HID). However, when the initial ID was least, both biocontrol treatments showed similar efficacy for ID reduction at the first sampling (15 DAP). In addition, the 
minimum values of ID reached during the assessment period were similar for the CGR03 and FO12 treatments. This confirms the effectiveness of these two biological treatments for reducing viable inoculum of $V$. dahliae in naturally infested soils, regardless of the initial ID of the pathogen. Nevertheless, neither of the two biocontrol treatments tested in this study eliminated inoculum of $V$. dahliae from the soil, and the pathogen was detected at all sampling times. Fluctuations in $V$. dahliae ID during the sampling period were observed. The increases in ID observed in July 2015 and July 2016 in the HID control microplots were similar to the results of LópezEscudero and Blanco-López (2001). They attributed these ID changes in July probable decreases in the superficial soil microbiota due to the high temperatures at that time of year. This change in microbiota could lead to high $V$. dahliae ID due probably to low microbial competition against the pathogen in the natural soil, or in the MSPA Petri dishes used for the assessment.

The similar levels of resistance to VWO of 'Picual' and 'Arbequina' observed in this study have been reported. Previous studies under controlled conditions reported that resistance of 'Arbequina' was overcome when plants were artificially inoculated by root dipping with a large amount of the pathogen $\left(10^{6}\right.$ conidia $\left.\mathrm{mL}^{-1}\right)$, with this cultivar showing the same level of resistance to VWO as the susceptible 'Picual' (López-Escudero et al., 2004). Nevertheless, in field studies carried out in naturally infested soils with ID levels ranging from 5 to $21 \mathrm{MS} \mathrm{g}^{-1}$, 'Arbequina' had greater resistance to VWO than 'Picual' (Trapero et al., 2013b). Similarly, an earlier study conducted under semi-controlled conditions in brick containers and using a naturally infested soil with moderate $V$. dahliae inoculum densities (9.8 $\mathrm{MS} \mathrm{g}^{-1}$ ) confirmed the greater VMO resistance of 'Arbequina' compared to 'Picual' (Pérez-Rodríguez et al., 2015). In the present study, with much greater initial pathogen IDs (83.6 and 23.6 MS $\left.\mathrm{g}^{-1}\right)$ ), both cultivars may have shown similar resistance to VWO due to the high inoculum pressure of the pathogen at the beginning of the experiment which overcame the genetic resistance of 'Arbequina'.

Plants treated with FO12 did not develop VWO symptoms over the experimental period. These results agree with those of Varo et al. (2016) and Mulero-Aparicio et al. (2019a), in which this $F$. oxysporum strain gave complete control of VWO in experiments conducted under controlled conditions. In studies evaluating the suppressive effects of organic amendments against $V$. dahliae, reductions of inoculum were correlated with reductions of disease progress in $80 \%$ of the cases (Bonanomi et al., 2007). In the present study, treatment with CGR03 reduced disease development in comparison with that in the control, but complete prevention of VWO was not achieved This was probably due to the presence of remaining inoculum to infect the plants. This is similar to the results of López-Escudero et al. (2007), who reported an initial ID of $0.04 \mathrm{MS} \mathrm{g}^{-1}$ was enough to infect olive plants of the susceptible 'Picual' and cause development of the disease.

Understanding the mechanisms of action of organic amendments in their effects against fungal diseases has become a challenge for researchers, due to their biological and chemical complexity. Organic compost based on cotton wastes reduced severity of Verticillium wilt of eggplant by triggering induced systemic resistance in host plants (Markakis et al., 2016). Furthermore, studies evaluating different olive mill waste composts showed that their suppressive effects against $V$. dahliae were due to biotic and abiotic factors (Papasotiriou et al., 2013). The mechanisms involved in the suppressive effects of the grape marc compost CGR03 remain unknown. Further research evaluating the roles of biotic and abiotic factors is required to improve the efficacy of this organic amendment against VWO.

Although FO12 was not the most efficient treatment for reducing ID of $V$. dahliae, its capability to (i) colonize the host plant rhizosphere, (ii) produce volatile organic compounds with antifungal effects, and (iii) produce chlamydospores that remain attached within host root systems (Mulero-Aparicio et al., 2019b). These could all play roles in its antagonistic effects against the pathogen by competing in the rhizosphere for infection sites, thus preventing the infection of olive roots by $V$. dahliae and achieving effective control of VWO. These traits have been previously observed in other nonpathogenic strains of $F$. oxysporum used as BCAs in herbaceous crops (Fravel et al., 2003). For instance, the non-pathogenic F. oxysporum strain F2 competed with $V$. dahliae for nutrients and space on root surfaces of eggplants (Pantelides et al., 2009). Similarly, the widely studied non-pathogenic F. oxysporum strain Fo47 has been reported to use different modes of action against $V$. dahliae, including induction of systemic resistance and competition for infection points on pepper plants (Veloso et al., 2016).

The effectiveness of these biocontrol products against $V$. dahliae shown in the present study confirms the consistency of these treatments, since they were previously reported as effective biocontrol treatments against $V$. dahliae in studies conducted under controlled conditions (Varo et al., 2016; Varo-Suárez et al., 2018; MuleroAparicio et al., 2019a) and in the field (Mulero-Aparicio et al., 2020). Consistency is considered one of the most important traits for biocontrol products (Deketelaere et 
al., 2017), since they are often known for their contradictory results between laboratory, semi-controlled and field conditions. Further research on the modes and times of application is needed to evaluate the efficacy and consistency of these products under different commercial field conditions, as well as further research on the mechanisms responsible for the suppressive effects of these agents and products.

In conclusion, the present study highlights the effectiveness of these two biocontrol treatments for reducing $V$. dahliae ID and progress of VWO under semi-controlled conditions. This study also expands knowledge about the use of biocontrol strategies as an eco-friendly approach to effective control of VWO, within an integrated disease management strategy. Although further research is needed to study the interactions of different biocontrol treatments with olive cultivars with different resistance levels in field conditions, the results obtained here indicate potential for applying these biocontrol treatments in $V$. dahliae-infested commercial fields, both before planting and during cultivation, to reduce initial pathogen inoculum pressure. This strategy, in combination with the use of moderately resistant olive cultivars, could be effective for the control of VWO.

\section{ACKNOWLEDGEMENTS}

This research was funded by the Spanish Ministry of Science, Innovation and Universities (MICINN; project AGL2016-76240-R), and co-financed by the European Union FEDER Funds. A.M.A. is the holder of a 'Formación de Profesorado Universitario' (FPU) fellowship from the Spanish Ministry of Education, Culture and Sports (MECD).

The authors declare that they have no conflicts of interest.

\section{LITERATURE CITED}

Analytical Software, 2013. Statistix10. User's manual. Tallahassee, FL.

Bonanomi G., Antignani V., Pane C., Scala F., 2007. Suppression of soilborne fungal diseases with organic amendments. Journal of Plant Pathology 89: 311-324.

Butterfield E.J., DeVay J.E., 1977. Reassessment of soil assays for Verticillium dahliae. Phytopathology 67: 1073-1078.

Campbell C.L., Madden L.V., 1990. Introduction to plant disease epidemiology. John Wiley and Sons Ltd, New York, NY, USA.
Deketelaere S., Tyvaert L., França S.C., Höfte M., 2017. Desirable traits of a good biocontrol agent against Verticillium wilt. Frontiers in Microbiology 8: 1186.

Fravel D.R., Olivain C., Alabouvette C., 2003. Fusarium oxysporum and its biocontrol. New Phytologist 157: 493-502.

Gómez-Lama C., Sesmero R., Valverde-Corredor A., López-Escudero F.J., Mercado-Blanco J., 2017. A split-root system to assess biocontrol effectiveness and defense-related genetic responses in aboveground tissues during the tripartite interaction Verticillium dahliae-olive-Pseudomonas fluorescens PICF7 in roots. Plant and Soil 417: 433-452.

Huisman O.C., Ashworth Jr L.J., 1974. Quantitative assessment of Verticillium albo-atrum in field soils: procedural and substrate improvements. Phytopathology 64: 1043-1044.

Jiménez-Díaz R.M., Trapero-Casas J.L., Boned J., Landa B., Navas-Cortés J.A., 2009. Uso de Bioten para la protección biológica de plantones de olivo contra la Verticilosis causada por el patotipo defoliante de Verticillium dahliae. Boletín de Sanidad Vegetal Plagas 36: 595-615.

Lima G., De Curtis F., D'Onghia A.M., Nigro F., 2007. Comparison between real-time PCR and semiselective medium in monitoring Verticillium dahliae microsclerotia in the olive rhizosphere and suppression of the pathogen by compost. IOBC/WPRS Bulletin 30: 221-224.

López-Escudero F.J., Blanco-López M.A., 2001. Effect of a single or double soil solarization to control Verticillium wilt in established olive orchards in Spain. Plant Disease 85: 489-496.

López-Escudero F.J., del Río C., Caballero J.M., BlancoLópez M.A., 2004. Evaluation of olive cultivars for resistance to Verticillium dahliae. European Journal of Plant Pathology 110: 79-85.

López-Escudero F.J., Blanco-López M.A., 2005. Isolation and morphologic characterization of microsclerotia of Verticillium dahliae isolates from soil. Biotechnology 4: 296-304.

López-Escudero F.J., Blanco-López M. A., 2007. Relationship between the inoculum density of Verticillium dahliae and the progress of Verticillium wilt of olive. Plant Disease 91: 1372-1378.

López-Escudero F.J., Roca J.M., Mercado-Blanco J., Valverde-Corredor A., Blanco-López M.A., 2010. Verticillium wilt of olive in the Guadalquivir Valley (southern Spain): relations with some agronomical factors and spread of Verticillium dahliae. Phytopathologia Mediterranea 49: 370-380.

López-Escudero F.J., Mercado-Blanco J., 2011. Verticillium wilt of olive: A case study to implement an 
integrated strategy to control a soil-borne pathogen. Plant and Soil 344: 1-50.

Lozano-Tovar M.D., Ortiz-Urquiza A., Garrido-Jurado I., Trapero-Casas A., Quesada-Moraga E., 2013. Assessment of entomopathogenic fungi and their extracts against a soil-dwelling pest and soil-borne pathogens of olive. Biological Control 67: 409-420.

Markakis E.A., Fountoulakis M.S., Daskalakis G.C., Kokkinis M., Ligoxigakis E.K., 2016. The suppressive effect of compost amendments on Fusarium oxysporum f. sp. radicis-cucumerinum in cucumber and Verticillium dahliae in eggplant. Crop Protection 79: 70-79.

Mehta C.M., Palni U., Franke-Whittle I.H., Sharma A.K., 2014. Compost: its role, mechanism and impact on reducing soil-borne plant diseases. Waste Management 34: 607-622.

Mercado-Blanco J., Rodríguez-Jurado D., Hervás A., Jiménez-Díaz R.M., 2004. Suppression of Verticillium wilt in olive planting stocks by root-associated fluorescent Pseudomonas spp. Biological Control 30: 474-486.

Mulero-Aparicio A., Agustí-Brisach C., Varo A., LópezEscudero F.J., Trapero A., 2019a. A non-pathogenic strain of Fusarium oxysporum as a potential biocontrol agent against Verticillium wilt of olive. Biological Control 139. https://doi.org/10.1016/j.biocontrol.2019.104045.

Mulero-Aparicio A., Cernava T., Turrà D., Schaefer A., Di Pietro A., López-Escudero F.J., Trapero A., Berg G., 2019b. The role of volatile organic compounds and rhizosphere competence in mode of action of the non-pathogenic Fusarium oxysporum FO12 towards Verticillium wilt. Frontiers in Microbiology 10:1808.

Mulero-Aparicio A., Varo A., Agustí-Brisach C., LópezEscudero F.J., Trapero A., 2020. Biological control of Verticillium wilt of olive in the field. Crop Protection 128. https://doi.org/10.1016/j.cropro.2019.104993.

Papasotiriou F.G., Varypatakis K.G., Christofi N., Tjamos S.E., Paplomatas E.J., 2013. Olive mill wastes: a source of resistance for plants against Verticillium dahliae and a reservoir of biocontrol agents. Biological Control 67: 51-60.

Pantelides I.S., Tjamos S.E., Striglis I.A., Chatzipavlidis I., Paplomatas E.J., 2009. Mode of action of a non-pathogenic Fusarium oxysporum strain against Verticillium dahliae using Real Time QPCR analysis and biomarker transformation. Biological Control 50: 30-36.

Pegg G.F., Brady B.L., 2002. Verticillium wilts. CAB International, Wallingford.

Pérez-Rodríguez M., Alcántara E., Amaro M., Serrano N., Lorite I.J., ... López-Escudero F.J., 2015. The Influ- ence of irrigation frequency on the onset and development of Verticillium wilt of olive. Plant Disease 99: 488-495.

Roca L.F., Moral J., Trapero C., Blanco-López M.A., López-Escudero F.J., 2015. Effect of inoculum density on Verticillium wilt incidence in commercial olive orchards. Journal of Phytopathology 164: 61-64.

Trapero C., Díez C.M., Rallo L., Barranco D., LópezEscudero F.J., 2013a. Effective inoculation methods to screen for resistance to Verticillium wilt in olive. Scientia Horticulturae 162: 252-259.

Trapero C., Serrano N., Arquero O., Del Río C., Trapero A., López-Escudero F.J., 2013b. Field resistance to Verticillium wilt in selected olive cultivars grown in two naturally infested soils. Plant Disease 97: 668674.

Triki M.A., Hadj-Taieb S.K., Mellouli I.H., Rhouma A., Gdoura R., Hassairi A., 2012. Identification and screening of bacterial isolates from Saharan weeds for Verticillium dahliae control. Journal of Plant Pathology 94: 305-311.

Varo A., Raya-Ortega M.C., Trapero A., 2016. Selection and evaluation of microorganisms for biocontrol of Verticillium dahliae in olive. Journal of Applied Microbiology 121: 767-777.

Varo A., Mulero-Aparicio A., Adem M., Roca L.F., RayaOrtega M.C., ... Trapero A., 2017. Screening water extracts and essential oils from Mediterranean plants against Verticillium dahliae in olive. Crop Protection 92: 168-175.

Varo-Suárez A., Raya-Ortega M.C., Agustí-Brisach C., García-Ortíz-Civantos C., Fernández-Hernández A., ... Trapero A., 2018. Evaluation of organic amendments from agro-industry waste for the control of Verticillium wilt of olive. Plant Pathology 67: 860870.

Veloso J., Alabouvette C., Olivain C., Flores V., Pastor V., García T., Díaz J., 2016. Modes of action of the protective strain Fo47 in controlling Verticillium wilt of pepper. Plant Pathology 65: 997-1007.

Vitullo D., Altieri R., Esposito A., Nigro F., Ferrara M., Alfano G., Ranalli G., De Cicco V., Lima G., 2013. Suppressive biomasses and antagonist bacteria for an eco-compatible control of Verticillium dahliae on nursery-grown olive plants. International Journal of Environmental Science and Technology 10: 209-220. 